BISMA

(Bisnis dan Manajemen)

\title{
Peningkatan Kapasitas dan Kualitas Pengolahan Produk Hasil Laut di Surabaya untuk Menembus Pasar Ekspor
}

\author{
Erna Ferrinadewi Kusnarsiyah \\ Universitas Widya Kartika \\ Email korespondensi: ferrinadewi@gmail.com
}

\begin{abstract}
In an effort to exploit Indonesia's rich marine potential of a variety of fish and given the large contribution of the growth of the fishery sector to Indonesia's gross domestic product, the seafood processing industry needs to improve the competitiveness of its products in order to increase the value of sea-based exports which in turn will improve the welfare of the community. SMEs engaged in the processing of seafood have not utilized science and technology in the production process so that found obstacles in the speed and fulfillment of export demand to neighboring countries. There are many work errors so shipping the product does not meet the standard of demand. The length of time the SMEs in fulfilling the buyer demand is caused by the length of the production process into the product ready to send. This work error results in the quality of the delivered product not meeting the health standards and the buyer's request. The ergonomic sorting table provides $2 \%$ reduction in work errors and the provision of wash tables designed to reduce work fatigue and the use of heating ovens to replace the sunlight function of the Cucumber products can increase the employee's working speed from 4 days to 2 days to prepare the product to send.
\end{abstract}

Keywords : Production capacity;Product Quality;Fish Belly Bubbles;Seafood Export

Received: 31 Agustus 2017 Reviewed: 10 Oktober 2017

Accepted: 30 Oktober 2017

Published: 31 Oktober 2017

\section{PENDAHULUAN}

Indonesia adalah negara kepulauan terbesar di dunia dengan luas lautan mencapai 1,9 juta kilometer persegi yang membentang sejauh 5000 kilometer dari barat ke timur. Besarnya wilyah lautan di negeri ini tentunya menyimpan banyak potensi hasil laut yang dapat dimanfaatkan untuk pertumbuhuan ekonomi Indonesia mengingat data BPS menyebutkan sekitar 7,87 juta jiwa atau 25,14 persen dari total penduduk miskin nasional menggantungkan hidupnya dari laut. Mereka tersebar di 10.666 desa pesisir yang berada di 300 dari total 524 kabupaten dan kota seIndonesia.

Potensi kelautan Indonesia terhampar di wilayah Nasional dari Sabang sampai Merauke yang tersusun dalam satu hamparan pulau besar dan kecil yang jumlahnya 17.508 buah pulau yang memiliki garis pantai terpanjang nomor dua di dunia (81.000 
km). Bahkan kekayaan laut Indonesia mampu berkontribusi pada kebutuhan perikanan global mencapai $10 \%$. Kenyataan ini sekaligus menunjukkan peluang Indonesia sebagai produsen hasil laut untuk memenuhi kebutuhan internasional tidak saja lokal.

Sesuai dengan visi dan misi Pemerintah menjadikan Indonesia sebagai poros maritim dunia, juga menjadikan laut sebagai masa depan bangsa. Menjadi poros maritim dunia berarti bangsa ini harus menggantungkan hidupnya pada laut, karena itu laut haruslah kaya ikan dan dimanfaatkan dengan sebaik mungkin agar bernilai tambah. Indonesia dengan potensi sumber daya laut yang melimpah ini, sewajarnya dapat memanfaatkan peluang ekspor yang tinggi ini.

Tabel 1. Data Pertumbuhan PDB

\begin{tabular}{lrrr}
\hline \multicolumn{1}{c}{ PDB LAPANGAN USAHA } & \multicolumn{1}{c}{$\mathbf{2 0 1 4}$} & \multicolumn{1}{c}{$\mathbf{2 0 1 5}$} & \multicolumn{1}{c}{$\mathbf{2 0 1 6}$} \\
\hline \hline A. Pertanian, Kehutanan, dan Perikanan & $1.129 .052,70$ & $1.171 .578,70$ & $1.209 .687,20$ \\
\hline $\begin{array}{l}\text { 1. Pertanian, Peternakan, Perburuan dan Jasa } \\
\text { Pertanian }\end{array}$ & $880.389,50$ & $906.804,50$ & $935.455,10$ \\
\hline a. Tanaman Pangan & & & \\
\hline b. Tanaman Hortikultura & $268.426,90$ & $280.018,80$ & $287.100,70$ \\
\hline c. Tanaman Perkebunan & $124.300,90$ & 127.110 & $130.527,10$ \\
\hline d. Peternakan & $338.502,20$ & $345.164,90$ & $357.234,80$ \\
\hline e. Jasa Pertanian dan Perburuan & $132.221,10$ & $136.936,40$ & $142.459,60$ \\
\hline 2. Kehutanan dan Penebangan Kayu & $16.938,40$ & $17.574,40$ & $18.132,90$ \\
\hline 3. Perikanan & $59.573,50$ & $60.757,40$ & $59.708,90$ \\
\hline
\end{tabular}

Berdasarkan data diatas dapat diketahui tingginya pertumbuhan sektor Perikanan berdasarkan data tahun 2014-2016. Meskipun terjadi penurunan signifikan pada pertumbuihan PDB 2015-2016 namun pertumbuhan sektor perikanan masih tertinggi dibanding sektor lain pada lapangan usaha Pertanian Kehutanan dan Perikanan. Hal ini menunjukkan besarnya potensi hasil laut Indonesia terhadap angka Produk Domestik Bruto. Dapat dikatakan hasil laut Indonesia memiliki potensi besar untuk dikembangkan. Data ini diperkuat dengan kenyataan bahwa dalam kurun waktu 4 tahun, 2012-2016 ekspor ikan indonesia meningkat sekitar 7.34\% dan untuk nilai ekspor naik sekitar 4,28\% dan untuk impor mengalami penurunan sekitar $14.83 \%$.

Namun sayangnya besarnya peluang dan potesni hasil laut Indonesia belum dapat dimanfaatkan oleh eksportr secara maksimal karena berbagai hambatan. Salah satu hambatan ekpor hasil laut Indonesia adalah persyaratan yang diminta pihak importir belum dapat dipenuhi diantaranya persyaratan kualitas kesehatan dan keamanan. Pihak importir mempersyaratkan adanya sertifikasi yang menjamin bahwa produk laut Indonesia didapatkan dengan cara yang benar sehingga pihgak importir tidak ragu dalam mengkonsumsi (djpen.kemendag.go.id).

Eksportir Indonesia mengalami kesulitan dalam memenuhi standar dan aturan kualitas pangan yang berbeda-beda untuk tiap negara importir bahkan setelah 
ratifikasi langkah-langkah Perjanjian Sanitary dan Phytosanitary (Agreement on Sanitary and Phytisabitary /SPS) dan perjanjian Hambatan Teknis Pada Perdagangan (Agrreement on Tehnical Barriers to Trade/TBT) dibawah WTO, masih saja terjadi perbedaan persyaratan di tiap negara importir bahka menciptakan hambatan perdangan non-tariff (meacenter.kpp.go.id).

Perabedaan tiap negara ini disebabkan karena banyak pemerintah negara importir meningkat kepeduliannya terhadap keamanan dan mutu makanan dan ini mendorong mereka meningkatkan aturan standar jaminan kualitas yang tinggi pada produk impor hasil laut. Kondisi ini seharusnya mendorong eksportir hasil laut indonesia untuk melakukan peningkatan mutu kualitas produk. Study yang dilakukan oleh Rahmawaty et.al. (2013) menunjukkan bahwa produktivitas dan ekspor hasil laut di Indonesia harus dibarengi dengan peningkatan mutu kualitas dan juga keamanan produk sebagai salah satu upaya peningkatan daya saing produk ekspor hasil laut Indonesia. Peningkatan daya saing hasill laut secara menyeluruh juga memerlukan pengembangan proses produksi, penanganan pasca panen dan pengolahan produk agar kualitas yang dihasilkan mampu bersaing dengan negara eksportir lain (Sirait, 2013).

Peningkatan mutu kualitas produk hasil laut pada gilirannya akan meingkatkan daya saing produk di pasar. Menurut Yunaifah (2017) salah satu nilai utama yang harus bisa dipenuhi oleh produsen suatu produk untuk dapat meningkatkan daya saingnya adalalah operational excellence yaitu dimana produsen harus mampu menjaga efisiensi dan meningkatkan kualitas dari system / proses penghasil produk maupun system pelayanan yang diberikan untuk senantiasa dapat memuaskan konsumen.

Menjaga dan meningkatkan mutu kualitas produk yang dihasilkan agar sesuai dengan standar permintaan importir pada akhirnya upaya ini akan meningkatkan kepercayaan importir terhadap produk eksportir sehingga volume ekspor dapat terus ditingkatkan (Listiani, 2013) Sayangnya banyak produksi Indonesia yang saat ini masih belum memenuhi standar kualitas terutama untuk tujuan eksor. Kualitas produk Indonesia masih belum memenuhi standar keselamatan dan kesehatan nasional. Keadaan ini tidak saja terjadi pada prokduk hasil industri melainkan juga produk yang berbasis sumber daya alam. Saat ini Produk berbasis sumber daya alam menguasai $65 \%$ total produk ekspor Indonesia.

Hal yang sama terjadi di UKM UD Mega Mandiri yang bergerak dalam usaha penyediaan produk gelembung perut ikan dan teripang belum memiliki standar produksi yang memenuhi standar kualitas permintaan pembeli di luar negeri. Seperti pada umumnya UKM, pengembangan produk UKM UD Mega Mandiri terkendala pada kemampuan aplikasi teknologi dan kurangnya pengembangan standarisasi yang konsisten

Kondisi ini sangat disayangkan mengingat perairan Indonesia banyak ditemukan berbagai jenis ikan dan pada kenyataannya gelembung perut ikan juga 
banyak diminati terutama pasar ekspor. Meskipun hingga saat ini belum ada data lengkap tentang permintaan gelembung perut ikan namun dapat diketahui dalam produk gelembung perut ikan dan teripang Indonesia bersaing dengan negara Vietnam, Thailand dan Jepang. UKM Mega Mandiri hingga saat ini bersaing dalam penawaran gelembung kulit ikan dan teripang di pasar Cina, Hongkong dan Singapura

Artikel ini bertujuna untuk menggkaji apa saja yang dpat dilakukan UKM Mega Mandiri untuk meningkatkan kapasitas dan kualitas produksi sehingga mampu memenuhi standar permintaan ekspor.

\section{METODE PENELITIAN}

\section{Jenis Penelitian}

Penelitian ini adalah penelitian kualitatif, untuk mengetahui perubahan kapasitas produksi dan mutu kualitas produk berbasis Ilmu Pengetahuan dan Teknologi pada industri pengolahan hasil di Surabaya untuk meningkatkan daya saing produk ekspor hasil laut setelah proses pelatihan dan pendampingan pemanfaatan iptek dalam proses produksi. Penelitian ini akan mengkaji secara kualitatif hambatan-hambatan yang dihadapi UKM dalam meningkatkan kapasitas produksi dan mutu kualitas produk.

\section{Metode Pengumpulan Data}

Obyek Penelitian ini adalah UKM CV Mega Mandiri yang berlokasi di Surabaya dan bergerak di bidang pengolahan hasil laut gelembung perut ikan dan teripang untuk tujuan ekspora. Data dikunpulkan dengan metode observasi dan dilengkapi dengan wawancara mendalam untuk mengetahui kapasitas produksi UKM dan sejauh mana UKM dalam mencapai dan memepetahankan mutu kualitas produknya.

\section{Metode Analisa Data}

Metode analisa data yang digunakan adalah analisa deskriptif dengan penekanan deskripsi situasi kapasitas produksi dan mutu kualitas produk dan memberikan penjelasan persoalan yang dihadapi UKM sehingga dapat memecahkan persoalan yang dihadapi UKM.

\section{HASIL DAN PEMBAHASAN}

UD Mega Mandiri adalah UKM yang bergerak di bidang pengolahan hasil laut menjadi produk dried seafood, berikut produk yang dihasilkan UKM. (1) Dried Seafood berupa daging perut ikan Gulama, ikan kakap Cina jantan dan betina, Ikan Kakap Putih Ikan Kerapu, Ikan Kurau. Ikan Katak Manyung. (2) Dried Seafood berupa Teripang. (3) Dried Seafood berupa Sirip ikan Hiu putih, Sirip, ikan Hiu Hitam dan Sirip ikan hiu kikir. 


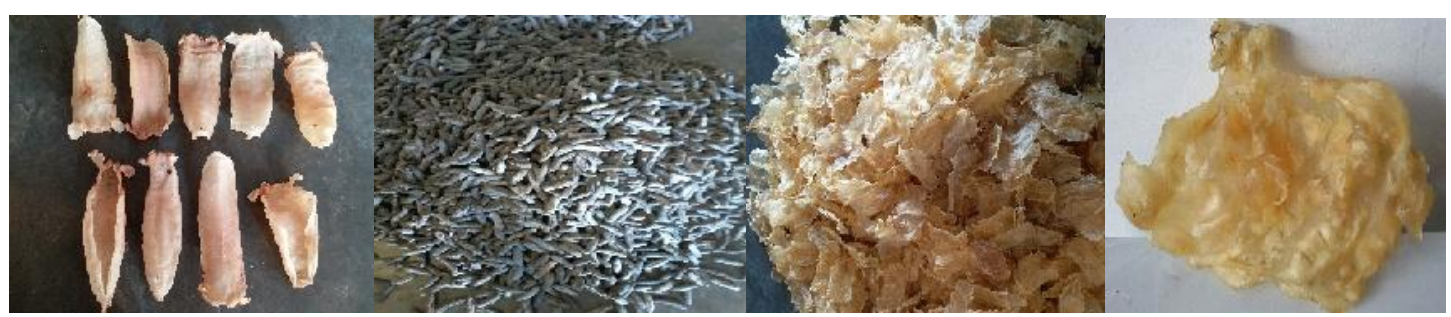

\section{Gambar 1 Produk Mega Mandiri}

Dari gambar 1 dapat dilihat produk-produk dried seafoof yang diproduksi oleh Mega Mandiri cukup banyak variasinya hal ini sesuai dengan kenyataan begitu kaya perairan Indonesai akan berbagai jenis ikan. Namun sayangnya produk Mega Mandiri masih diolah dengan teknologi sederhana mengandalkan tenaga manusia dan sangat bergantung pada cuaca terutama kebutuhan panas dan cahaya matahari untuk proses pengeringan sebelum produk siap kirim.

Pasokan bahan mentah diperoleh dari nelayan di perairan Merauke dan Surabaya yang jumlahnya sangat bergantung pada musim dan cuaca alam. Sebelum dikirim ke Surabaya, nelayan telah terebih dahulu memproses hasil tangkapan mereka dengan memisahkan antara daging dan gelembungnya untuk selanjutnya dikeringkan dan dikirim dengan pesawat. Hasil proses nelayan ini tentunya masih sangat sederhana dan hasilnya pun masih jauh dari standar permintaan pembeli karena dikerjakan dengan peralatan sangat sederhana dan mengandalkan keterampilan secara tradisional tanpa standar tertentu. Pengeringannya dilakukan alakadarnya dengan panas matahari dengan faktor kebersihan yang tidak diperhitungkan nelayan.

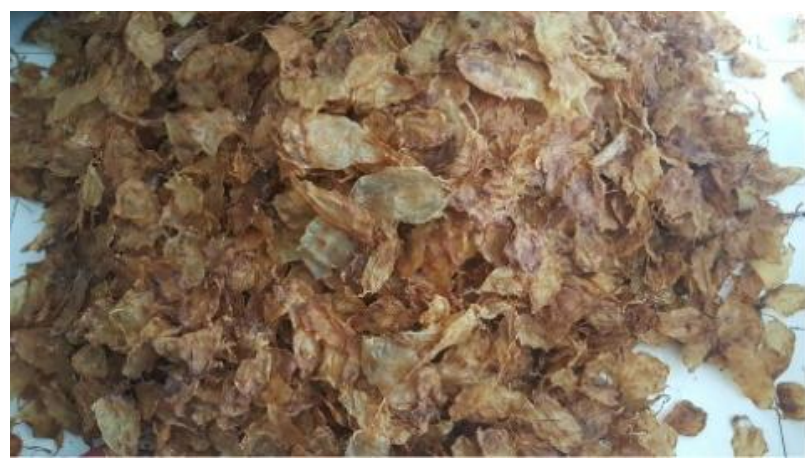

Gambar 2. Hasil Proses tradisional nelayan

Proses pertama adalah melakukan sortir bahan mentah berdasarkan size gelembung kulit ikan. Sortir ini dilakukan dengan tenaga manusia tanpa alat teknologi apapun. Kesalahan sering terjadi ketika pekerja salah menentukan size. Proses sortir dilakukan 2x. Proses sortir kedua dilakukan setelah produk selesai proses pencucian. Proses sortir ke 2 ini dilakukan berdasarkan berat. Proses sortir 
kedua ini perlu dilakukan mengingat setelah proses pencucian, gelembung perut ikan dan sehingga mengalami perubahan berat karena telah bersih dari minyak dan debu. Sebelumnya proses ini dikerjakan di lantai tanpa alat bantu apapun. Banyak terjadi kesalahan kerja pada proses ini diantaranya kesalahan dalam menempatkan produk ke kelompok size yang benar sehingga terjadi perbedaan ukuran dalam 1 kelompok. Posisi tubuh yang salah saat bekerja lebih cepat menimbulkan kelelahan. Berbagai studi membuktikan menurunnya produktivitas akibat posisi kerja yang tidak nyaman (Karakolis \& Callaghan, 2014) Diperlukan meja yang ergonomis sehingga mampu mengurangi kelelahan kerja sekaligus meningkatkan kecepatan kerja. Produktivitas pekerja sangat bergantung pada desain ergonomis lokasi kerjanya (Shinde dkk., 2012) Penggunaan meja sortir yang bersih dengan pembatas di tepian mencegah produk jatuh ke lantai, juga di desain dengan ketinggian yang memungkinkan pekerja melakukan sortir dengan posisi duduk di kursi ternyata mampu mengurangi kesalahan kerja hingga 2\% saja dan meningkatkan kecepatan kerja hingga 2 hari lebih cepat dari sebelum penggunaan meja sortir.

Untuk mendapatkan produk hasil laut dengan daya saing yang tinggi, bahan mentah harus di proses ulang kembali. Proses pencucian menjadi hal kedua setelah sortir berdasarkan size selesai dilakukan. Proses ini terutama harus dilakukan khususnya pada gelembung ikan Kakap Putih dan gelembung ikan Kurau juga Teripang. Kotoran dan minyak/ lemak sering menjadi masalah pada gelembung ikan Kakap Putih dan ikan Kurau. Sedangkan kotoran yang menempel pada Teripang pada umumnya adalah debu. Pencucian dilakukan dengan cara-cara sederhana tanpa alat. Pencucian dilakukan di lantai dengan alat seadanya dan tanpa memperhatikan faktor kebersihan. Untuk mencapai standar kesehatan produk dried seafood, Mega Mandiri dibuatkan meja cuci terbuat dari plat besi setebal $2 \mathrm{~mm}$ yang di desain dengan aliran air yang mengalir dan ketinggian meja tidak membuat proses pencucian menjadi melelahkan untuk karyawan. Proses pencucian ini menggunakan alat yang mengandalkan air mengalir sehingga tidak terjadi genangan air di area cuci. Oleh karena itu, meja cuci didesain untuk dapat dikerjakan baik dengan posisi duduk maupun dengan posisi berdiri. Jika proses ini dilakukan dengan posisi berdiri maka akan menimbulkan kelelahan pada otot (Halim dkk., 2012). Posisi kerja kombinasi duduk dan berdiri seperti ini akan mencegah kelelahan sehingga tidak mengurangi produktivitas kerja (Karakolis \& Callaghan, 2014). Meja cuci digunakan untuk memastikan produk terjaga kebersihannya dari kuman atau kotoran di lantai mengingat produk adalah makanan dan pencucian yang baik serta bersih akan mencegah timbulnya jamur dan bakteri (Giri dkk., 2011).

Pengeringan dilakukan hanya mengandalkan cahaya dan panas matahari. Panas matahari yang seringkali menjadi kendala utama dalam proses pengeringan karena panas yang tidak maksimal dan berubah-ubah mengikuti alam membuat produksi menjadi terhambat karena dibutuhkan waktu 4 hari untuk mencapai tingkat kering yang maksimal pada produk teripang. Khusus produk Teripang menggunakan alat pemanas yang memangkas waktu pengeringan dari 4-5 hari menjadi 1 hari saja. 
Pengeringan yang maksimal ini diperlukan untuk produk hasil laut yang akan di ekspor karena dalam kondisi kering pertumbuhan jamur dan bakteri dapat dihindari ( Bellagha dkk., 2007). Negara importir tidak akan mentoleransi produk hasil laut yang mengandung jamur atau bakteri.

Secara keseluruhan area kerja Mega Mandiri perlu di evaluasi tata letaknya mengingat tata letak pabrik di desain untuk mengatur penempatan fasilitas dalam cara yang paling ekonomis untuk memenuhi kebutuhan produksi baik segi kuantitas dan kualitas (Wanniarachchi,2016) . Berbeda dengan pabrik manufaktur, pada industri makanan tata letaknya disesuaikan dengan beberapa keunikan seperti adanya proses pencucian dan pengeringan, proses sortir ukuran dan berat material, dan proses lain yang tidak ada pada perusahaan manufaktur. Tata letak pabrik Mega Mandiri ditata sedemikian rupa sesuai dengan urutan kerja dengan mempertimbangkan kebersihan dan kesehatan produk Kebersihan area kerja Mega Mandiri perlu diperhatikan mengingat produk akhirnya adalah makanan yang nantinya akan dikonsumsi. Area kerja yang sehat dan bersih perlu dikelola, fasilitas kerja seperti mesin penimbang, area cuci, area pengepakan, gudang penyimpanan dan area administrasi ditempatkan untuk menunjang efisien produksi dan kualitas produksi.

Peralatan pencucian dan pengeringan diletakan di area depan pabrik karean dibutuhkan aliran air limbah ke luar pabrik dan ventilasi terbuka udara cukup luas untuk proses pengeringan baik dengan oven maupun dengan memanfaatkan panas dan cahaya matahari. Peralatan sortir seperti meja sortir, kursi dan alat timbang diletakkan di belakang area adminsitrasi dengan penambahan lampu sorot yang cukup terang untuk mencegah kesalahn sortir, disediakan juga fan di atas agar pekerja nyaman dan terhindar dari kelelahan. Peralatan untuk pengemasan produk siap kirim diletakkkan di area depan gudang, hal ini dilakukan untuk memmpermudah pekerja dalam mengambil produk yang disimpan di gudang dengan troley lebih dekat dan menghemat waktu pengerjaan. Gudang di pisahkan menjadi 3 ruangan dengan isi produk yang masing-masing memiliki kesamaan karakteristik. Pemyimpanan dilakukan dengan alas berupa palet plastik untuk menjamin kebersihan produk dan menghindaari kerusakan produk akibat udara lembab.

\section{KESIMPULAN}

Terlalu banyak kesalahan kerja yang terjadi dalam proses sortir seperti salah memisahkan produk yang sesuai dengan ukuran dan berat ke dalam tempat yang tepat. Faktor kelelahan pekerja menjadi penyebab dalam berbagai kesalahan kerja juga kurangnya pelatihan penggunaan alat membuat pekerja tidak teliti dalam penggunaan alat dan menyebabkan kesalahan hasil. Kesalahan ini menurun dengan pendampingan dalam penggunaan peralatan sehingga pekerja lebioh terlatih.

Keterlambatan dalam pemenuhan permintaan pembeli, diakibatkan karena ketergantungan Mega Mandiri pada pemanfaatan cahaya matahari dalam proses 
pengeringan terutama untuk produk Teripang yang dibutuhkan kekeringan hingga ke bagian dalam dan itu membutuhkan 3-4 hari jika menggunakan panas matahari saja. Penggunana iptek diperlukan dalam peningkatan kecepatan proses pengeringan sehingga produk dapat segera dikirim

Tata letak dalam pabrik diperlukan untuk meningkatkan kapasitas produksi melalui efisiensi kerja. Efisiensi kerja dapat didapatkan dengan penempatan peralatan produksi seperti meja sortir, meja pencucian, peralatan pengepakan, area administrasi, peralatan proses pengeringan dengan baik sesuai alur produk hingga produk siap dikirim ke pembeli.

UKM Mega Mandiri disarankan untuk berupaya memiliki HAACP Certificate untuk meningkatkan daya saing produk karena dengan memiliki sertifikat ini produk UKM masuk dalam kualifikasi produk makanan yang memenuhi standar kesehatan dan kebersihan makanan sehingga layak dikonsumsi. UKM diharapkan terus menerus memberikan pelatihan kepada karyawan agar kesalahan kerja semakin minimal sekaligus meningkatkan kecepatan kerja sehingga proses pengiriman pesanan dapat menjadi lebih singkat. Memiliki SOP tentang kebersihan dan kesehatan di area pabrik mengingat produk akhir UKM termasuk produk makanan yang akan di konsumsi sehingga proses kerja yang bersih dan sehat menjamin produk bebas bibit penyakit.

\section{REFERENSI}

Bellagha, A. Sahli, A. Farhat, N. Kechaou \& A. Glenza (2007). Studies on Salting and Drying of Sardine (Sardinella aurita) : Experimental Kinetics and Modeling. Journal of Fod Engineering, Volume 78, Isssue 3 P. 947-952

Giri A, Osako K, Okamoto A, Okazaki E, Ohshima T, (2011). Effect of meat washing on the development of impact odorants in fish miso prepared from spotted mackerel. Journal Science Food Agriculture. Volumen 91, Nomer 5, halaman 850-859

Halim, Isa, abdul Rahman Omar, Alias Mohd. Saman, Ibrahim Othman (2012), Assessment of Muscle Fatigue Associated with Prolong Standing in a Workplace. Safety and Heakth at Work, Volume 3, issue 1, P. 31-42

Karakolis, Thomas \& Jack P. Callaghan. (2014) The Impact of Sit-Stand Office Workstation om Worker Discomfort and Productivity : A Review. Applied Economics, Voume 45, Isssue 3, P. 799-806

Listiani, Nurlia (2012) Penerapan Standar Ekspor Gurita dan Ikan Teri Perusahaan Perikanan di Kendari. Buletin ilmiah Litbang Perdagangan, Volume 7, No,1 halaman 91-98

Rahmawat, Lely \& Winiati P. Rahayu \& Harsi D. Kusumaningrum, (2013), Pengembangan Strategi Keamanan Produk Perikanan Untuk Ekspor Ke Amerika Serikat, Jurnal Standarisasi, Volume 16, No.2 halaman 95-102 
Shinde, MR Gutunath V \& V.S. Jadhav,(2012). Ergonomic Analysis of an Assembly Workstation to Identify Time Consuming and Fatigue Causing Factor Using Application of Motion Study. International Journal of Engineering and Techonolgy, Volumen 4. No.4. halaman 220-227

Sirait, Marleny. (2013) Kajian Pengembangan Perikanana Berbasis Komoditas Unggulan di kabupaten Muna. Jurnal Kelautan, Volume 6 no. 2

Wanniarachchi, W.N.C, Gopura, R.A.R \& Punchihewa, H.K.G, (2016), Development of Layout Model Suitable for the Food Processing Industry. Journal pf Industrial Engineering. Volume 2016.

Widyastutik \& Reni Kristina Arianti, (2014), Analisa Strategi Kebijakan Mutu dan Standar Produk Kayu Lapis dalam Rangka Meningkatkan Daya Saing Ekspor, Jurnal Agrobisnis Indonesia, Volume 2, No, 1 halaman 75-92 